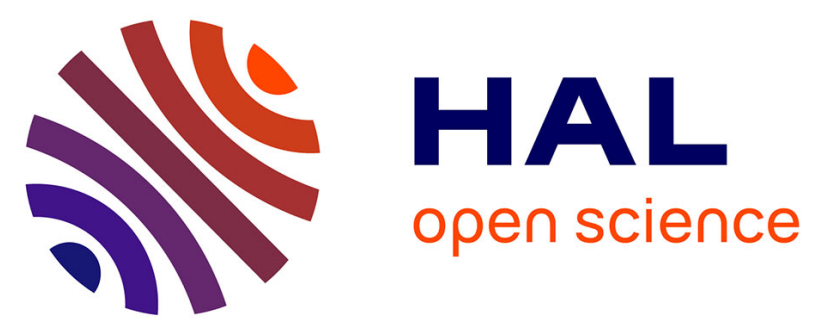

\title{
Impact of population ageing on hospital consumption and medical demography in metropolitan France: The example of obstetricians
}

Katsiaryna Kananovich, Jean-Marc Macé, E Yuryeva

\section{To cite this version:}

Katsiaryna Kananovich, Jean-Marc Macé, E Yuryeva. Impact of population ageing on hospital consumption and medical demography in metropolitan France: The example of obstetricians. Medical University, 2018, 1 (1), 10.2478/medu-2018-0004 . hal-02870760

\section{HAL Id: hal-02870760 https://hal.science/hal-02870760}

Submitted on 16 Jun 2020

HAL is a multi-disciplinary open access archive for the deposit and dissemination of scientific research documents, whether they are published or not. The documents may come from teaching and research institutions in France or abroad, or from public or private research centers.
L'archive ouverte pluridisciplinaire HAL, est destinée au dépôt et à la diffusion de documents scientifiques de niveau recherche, publiés ou non, émanant des établissements d'enseignement et de recherche français ou étrangers, des laboratoires publics ou privés.

\section{(ㅇ)(1) $\$$}

Distributed under a Creative Commons Attribution - NonCommercial - NoDerivatives 44.0 


\title{
IMPACT OF POPULATION AGEING ON HOSPITAL CONSUMPTION AND MEDICAL DEMOGRAPHY IN METROPOLITAN FRANCE: THE EXAMPLE OF OBSTETRICIANS
}

\author{
K. Kononovich ${ }^{1}$, Jean-Marc Macé1, E. Yuryeva²
}

${ }^{1}$ LIRSA research laboratory, National Conservatory of Arts and Crafts (Cnam)

${ }^{2}$ Department of Economics and management, V.F. Voino-Yasenetsky Krasnoyarsk State Medical University, Krasnoyarsk, Russian Federation

Abstract

The challenges of medical demography have become a major issue today in France, mainly because of the conjunction of two phenomena. Namely, a massive retirement of the "baby boom" generation and a delay in the medical training induced by the "numerus clausus" that had not anticipated that phenomenon. Unfortunately, the repercussion of the population ageing on hospital consumption and consequently on medical demography is very poorly integrated into the calculation and implementation of the medical professions' numerus clausus in 2010. Thus we suggest a model that not only identifies the effective demand for care on operational geographical scale, namely, the health territory, but that also makes a projection of healthcare consumption based on the age of population of each "health territory" in a $\mathrm{T}+1$ future. To illustrate this model, we take as example the obstetricians' activity in France.

Keywords

Territory operational experience $\bullet$ health territory $\bullet$ ageing population $\bullet$ territorial predictive modelling $\bullet$ medical demography

\section{Introduction}

The better territorial equity requires balance between supply and demand for care. But on which territory? At the local level, an operational infra-departmental territory or even suburban territory for large cities should be defined. The territorial consensus between participants can be reached by managing both the flows of users and the geographical distribution of specialists on French territory. Furthermore, the territory is not fixed in time, it changes in accordance with dynamics of its own population [1]. Among the determinants of health, the age variable is predominant in care consumption. The impact of population ageing on medical demography represents a significant issue today [2], but it is still not, unfortunately, properly integrated into the calculation and the implementation of the numerus clausus, i.e. a number of students admitted to each medical, dental, pharmaceutical and midwifery program after the first year of study [3]. So, it is legitimate for each discipline (medical, surgical, medical-surgical), or even for each specialty (urology, vascular surgery, obstetricians, etc.), to plan what their most likely activity would be in ten to fifteen years to come. The medical and surgical specialties assignment, introduced by the Hospital Patient Health Territory (HPST) law of July 21, 2009, allows now to manage the flows and to control the geographical distribution of specialists on the French territory according to the regional numerus clausus. It is a regulated number which is fixed each year in accordance with population needs in care. The challenges of medical demography have become a major issue in public health taking into account the conjunction of two phenomena such as massive retirements of the "baby-boom" generation and a delay in the medical training due to the numerus clausus $[4,5]$ that had not anticipated this phenomenon. However, it is necessary to identify the more precise population dynamics at the local level in order to determine the dynamics at regional level.

The purpose of this study is to analyse the effective demand for care in the context of massive retirement of "baby boom" generation practitioners and a delay in the medical training induced by the "numerus clausus" that had not anticipated that phenomenon. The following questions are raised: the real population health care consumption, how can it be assessed? The health care supply, does it meet the population effective demand for care at the regional level? And will it be the case in the coming years? The example of the obstetricians' activity in France will be studied. 


\section{Operational space network}

\section{Benchmark territory construction}

The territory, as it is defined in the dictionary of health geography of Henri Pichéral [6], can be spelled out through different aspects. The territory is a spatial organisation with well-defined borders where "any administrative and functional (health sector, supervision)... authority, power, competence are exercised. And in case if balance, equity is not provided or not well provided, it requires the territory planning by health care planning". But the territory is also a space "of a community with its routine, its lifestyle habits; the territory is perceived, it is viewed as a space experience (living area) ...." Thus the territory can be defined as a an administrative space predetermined by the authority and based on the principle of top-down management, as well as a living area (experience territory) designed by users' daily routine [7]. However, the experience territory remains unnoticed for a long time. This refers to the philosophical view of the subject as Berkeley's [8] immaterialism stating "esse is percipi aut percipere" (Being means to be perceived or to perceive), which questions the very existence of the territory experience. But also to Kant's [9] view and its concept of numen, an object of intellectual intuition, which brings to the concept of territory experience its right to exist (the territory is considered as a numen) [10]. Thus, it is necessary to study the daily practices of users, or the flows, to define the experience territory borders.

Since the end of the 1980s, the health geographers have been interested in defining the operational health territory [11, 12]. Many options have been explored in order to overcome an inappropriate and obsolete geographical division of "health sectorisation" resulting from the hospital law of $1970[13,14]$. The "Juppé Ordinances", which came into force in April 1996, have changed the hospital landscape as establishments had to provide each year the data of their activity to the newly created Regional Hospitalisation Agencies. Consequently, since 1999 the spatial activity of users can be tracked in each discipline or hospital specialty [15].

\section{Methods}

The methodology of this study is based on the setting up of the operational network. The application of the operational network technique in health geography is inspired by the Mirabel method of The National Institute of Statistics and Economic Studies (INSEE) proposed in 1975 by J-J Ronsac and C. Terrier. This method is initially based on the analysis of users' "home-work" flows in order to delimit the "employment territory" [16, 17].
To set up an operational network, the "departure-arrival" flows should be studied according to a given problematic (obstetrics, urology, etc.) by means of the "relative flow method". Transposed to the hospital area, the "home-health centre" users' flows are analysed. This method allows to define the territory operational experience based on users' spatial practices which doesn't necessarily coincide with administrative territory borders.

This territorial approach can be presented with a scheme. In Figure 1, each arrow symbolises, not only, the volume of hospitalised patients living on this territorial entity (municipality, postal code), but also the major orientation of hospitalisation flows (even in relative terms) living in each municipality or postal code. The method is based on a "descending sort" of each "place of departure" to all "place of arrival".

Figure 1. Relative major orientation of hospitalized patients to a hospital centre

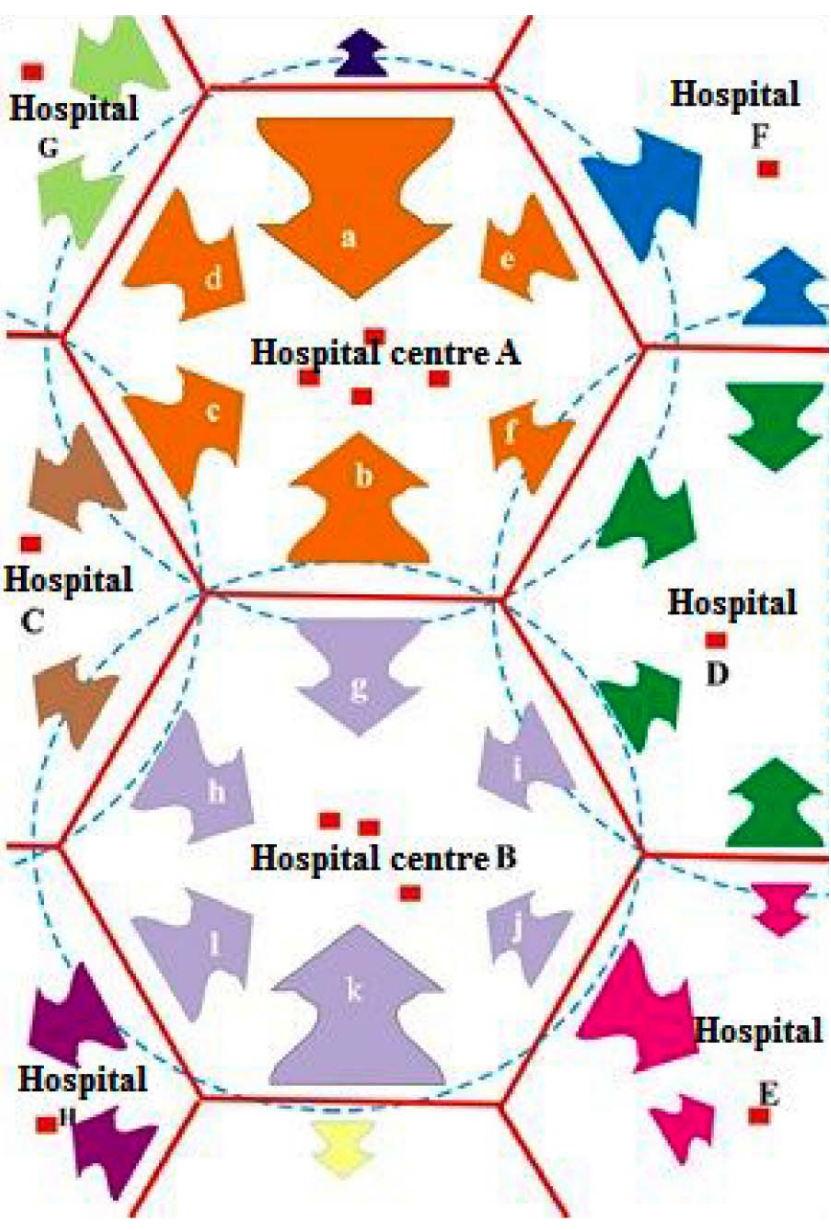

As a result, all municipalities (postal codes) are then classified without any overlap or omission, according to the importance of their place of departure and destination. All municipalities (or postal codes), whose major (even relative) flows of 
hospitalised patients are directed to the same hospital centre, belong and constitute a health territory. The formulation of this major orientation of hospitalised patients to a hospital centre is represented as:

Majority tie "Home - Hospital" $=\frac{\text { Hospitalised patients coming from the municipality "a" to the hospital center "A" }}{\sum \text { no }}$

\section{Where}

" $a$ » is a « departure » spatial entity of hospitalised patients ; « $A$ » is an « arrival » hospital centre of hospitalised patients;

As this analysis is carried out for a given discipline (obstetrics, etc.) or for a given specialty segment (births, etc.), it comes to defining a space which reflects a homogeneous spatial activity of hospitalised patients. This corresponds to a real "territory hospital experience".

\section{Results}

The operational territorial network of obstetricians in France

The analysis of the flows in the 545 maternity units in metropolitan France in 2015 allows to identify 328 lived birth territories (Map 1). There are 7000 practicing obstetricians in metropolitan France to cover 800,000 births annually; however, the practitioners' density is not homogeneous on each spatial entity $[18,19]$.

\section{Differentiated spatial dynamics}

The demographic dynamics are not the same on each health territory, so it is necessary to estimate the most probable changes in birth trend for the near future. For this purpose, we construct a "predictive model" for operational spatial entities based on the demographic structure changing over time.

\section{Predictive modelling}

This model proposes to estimate the healthcare consumption for "residents living on an operational territory" for the coming years (T1) [20]. Firstly, this model requires to identify the effective demand for hospital births at an operational geographical scale level in T0. Secondly, it proceeds to the projection of the number of hospital births according to population age structure on each health territory for T1 future. For this purpose, we perform a "standardization" according to age with the hospitalisation rates in T0, coming from Program for medicalization of the information systems (PMSI), on the age structure in T1 resulting from the OMPHALE-INSEE method $[21,22]$ on each health territory. The formula to

Map 1. Variation in hospital activity related to births in metropolitan France between 2009 and 2012.

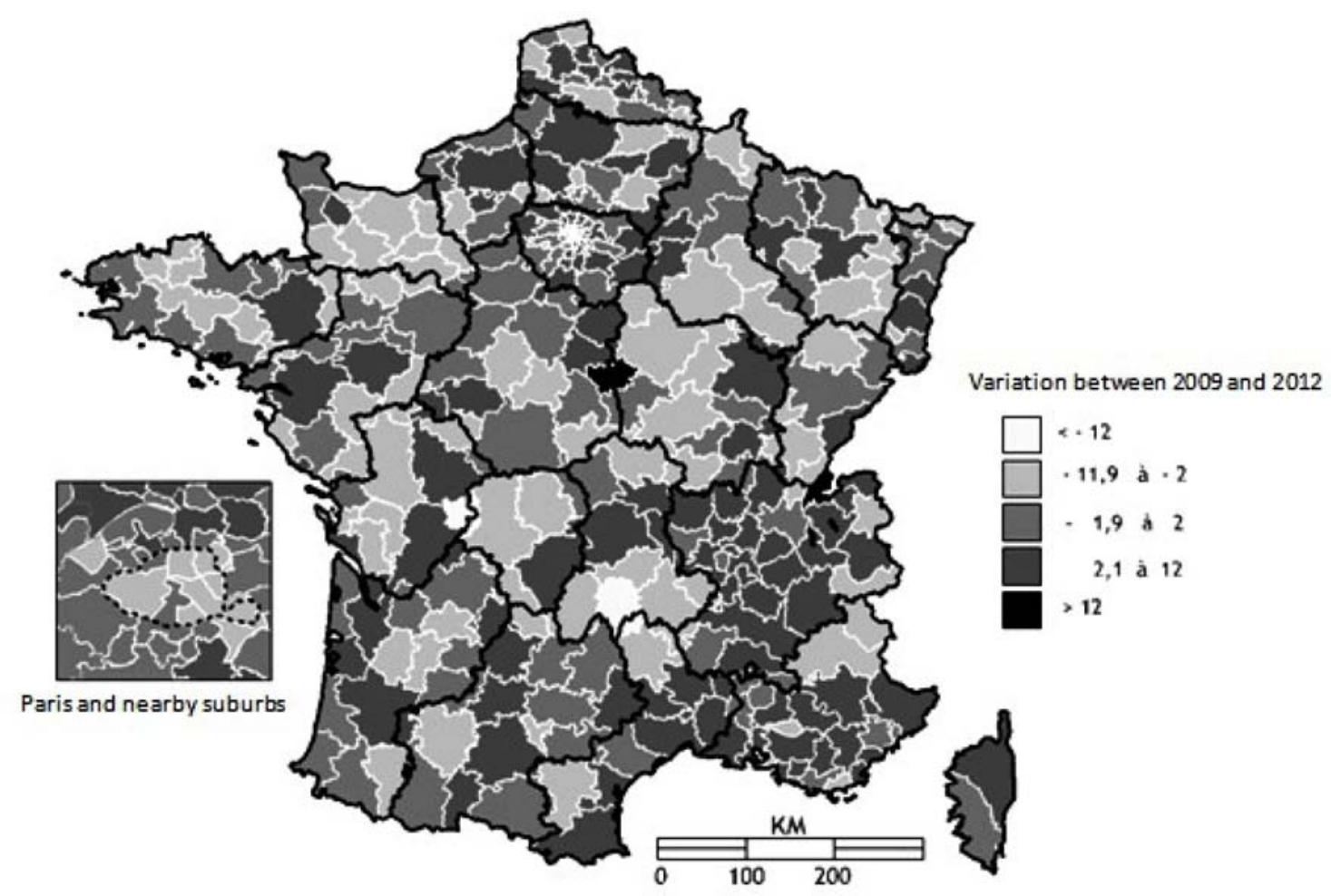


estimate hospital activity expected in T1 future on the spatial entity is expressed as follows:

$$
\operatorname{Exp} T 1=\sum_{k} P 1 \cdot t_{k T 0}
$$

Where:

Exp T1, is hospital activity on the spatial entity expected in T1; $\mathbf{k}$, is an age range;

$\mathbf{P 1}$, is the population size of $\mathrm{k}$ - age group in $\mathrm{T} 1$;

tkT0, is the hospital activity rate of each homogeneous patient age group $\mathrm{k}$ in $\mathrm{TO}$.

Thirdly and finally, the result obtained from the predictive model is compared to the situation really observed in $\mathrm{T} 1$. Thus, a weighting index to each spatial entity predictive model can be established as follows:

$$
\lambda=\frac{\operatorname{Exp} T 1}{\operatorname{Act} O b s T 1}
$$

Where:

$\lambda$ is a weighting index calculated on the basis of hospital activity between the period $\mathrm{T} 0$ and $\mathrm{T} 1$;

Act Obs T1, is hospital activity observed on the spatial entity in T1.

This weighting index is used then to calculate the activity projection for a T2 future which is more distant than T1. This weighting index $\lambda$ allows to correct the trend of the projections obtained from the initial predictive model and related only to the impact of population ageing on the hospital births. Thus, it means to take into account changes in the medical practices and the ways of hospitalisation between T0 and T1 for T2 future which remains unknown.

Thus, the formula to estimate hospital activity expected in T2 future on the spatial entity is expressed as follows:

$$
\operatorname{Exp} T 2=\sum_{k} P 2 \cdot t_{k T 0} \cdot \lambda
$$

Where:

ExpT2, is hospital activity expected in T2 future following T1 on the spatial entity;

$\mathbf{k}$, is a range of homogeneous patient group;

$\mathbf{P 2}$, is the population size of k-group in T2;

$\mathbf{t}_{\mathrm{kT0}}$, is the hospital activity rate of each homogeneous patient age group $\mathrm{k}$ in $\mathrm{TO}$;

$\lambda$ is a weighting index calculated between T0 and T1.

This model is reliable for T2. Indeed, according to the research study published in 2012, the test on slope of regression line states that the volume of activity weighted and expected in T2 does not show any significant difference compared with the volume of activity observed in T2 [23, 24].

\section{Matching between supply and demand by 2020}

The projection of hospital consumption related to births shows a slight growth at the national level between 2010 and 2020, i.e. $0.7 \%$ in 20 years. According to our model, the volume of hospital activity related to births in metropolitan France should rise from 777,800 acts (delivery and caesarean section) in 2010 to 783,100 acts in 2020, which amounts to an increase of 5,300 birth-related acts. However, this growth is far from being homogeneous across the country.

Finally, taking into account a consistent prospective vision means to group at the region level the results obtained at the local operational territories level. In this way, regional hospital demand related to births takes into account local features. In such a case, the numerus clausus related to the National Council of Universities (CNU) subsection of obstetricians should be increased in 3 regions, and decreased in île-deFrance (IDF) (Table 2).

\section{Discussion}

The proposed model allowed to evaluate the effective demand of population for obstetrician care via the operational geographical network. As illustrated, the current administrative geographical division does not reflect population spatial dynamics. So the territory operational experience should be taken into account for better planning the number of specialists on each health territory. In 2015 Metropolitan France has 7000 obstetricians to cover 800000 births per year, which corresponds to 114 acts on average per practitioner. However, the distribution of practitioners in France remains unequal $[25,26]$. The areas of attraction with a significant concentration of practitioners can be identified, such as Île-de-France with 1,813 practitioners for 179,053 births in 2010, Rhône-Alpes region with 671 practitioners for 80,095 births and PACA (Provence-Alpes-Côte d'Azur) with 669 practitioners for 58,927 births; as well as territories with a lower concentration of practitioners, such as Limousin and Franche-Comté. If some disparities in hospital care regarding the effective demand are identified, what would happen in the years to come? This question is significant in view of changes in medical demography marked by the massive retirement of practitioners and the numerus clausus application. Indeed, the calculation of numerus clausus, which role is to settle the number of practicing doctors by region, takes into account only the number of retired practitioners, but does not integrate the dynamic of effective demand. A simple replacement of retirements will not be enough to cover the effective demand on some health territories which population continues to rise. It risks creating an important imbalance between supply and the effective demand for care between health territories. 
Table 2. Estimated changes in number of obstetricians by region by 2020

\begin{tabular}{|c|c|c|c|c|c|c|}
\hline \multirow{3}{*}{$\begin{array}{c}\text { Year } \\
\text { Regions } \\
\text { Rhone Alpes }\end{array}$} & \multicolumn{2}{|c|}{2010} & \multicolumn{2}{|c|}{2020} & \multirow{2}{*}{\multicolumn{2}{|c|}{$\begin{array}{c}V^{*} 2009 / 2020 \\
\text { OB-GYN\&GYN Birth acts }\end{array}$}} \\
\hline & \multirow{2}{*}{$\frac{\text { OB-GYN\&GYN }}{671}$} & \multirow{2}{*}{$\frac{\text { Birth acts }}{80095}$} & \multirow{2}{*}{$\frac{\text { OB-GYN\&GYN }}{692}$} & \multirow{2}{*}{$\frac{\text { Birth acts }}{82400}$} & & \\
\hline & & & & & 21 & 2,88 \\
\hline PACA & 669 & 58927 & 683 & 60004 & 14 & 1,83 \\
\hline Midi Pyrenees & 297 & 31206 & 304 & 31885 & 7 & 2,18 \\
\hline Aquitaine & 364 & 33606 & 368 & 33766 & 4 & 0,48 \\
\hline Nord Pas de Calais & 424 & 55795 & 427 & 56131 & 3 & 0,60 \\
\hline Languedoc Roussillon & 243 & 28913 & 246 & 29248 & 3 & 1,16 \\
\hline Haute Normandie & 149 & 22282 & 151 & 22624 & 2 & 1,54 \\
\hline Pays de la Loire & 302 & 44633 & 304 & 44661 & 2 & 0,04 \\
\hline Centre & 226 & 29173 & 228 & 29379 & 2 & 0,71 \\
\hline Auvergne & 132 & 12952 & 133 & 12986 & 1 & 0,26 \\
\hline Bourgogne & 138 & 17499 & 139 & 17532 & 1 & 0,19 \\
\hline Picardie & 160 & 22925 & 161 & 23141 & 1 & 0,94 \\
\hline Poitou Charentes & 148 & 17486 & 149 & 17494 & 1 & 0.04 \\
\hline Alsace & 225 & 22009 & 226 & 22087 & 1 & 0,36 \\
\hline Bretagne & 297 & 36830 & 297 & 36770 & 0 & $-0,16$ \\
\hline Limousin & 56 & 7835 & 54 & 7591 & -2 & $-3,12$ \\
\hline Champagne Ardennes & 112 & 15759 & 110 & 15553 & -2 & $-1,31$ \\
\hline Lorraine & 245 & 26152 & 243 & 25865 & -2 & $-1,10$ \\
\hline Franche Comte & 89 & 14342 & 86 & 13927 & -3 & $-2,90$ \\
\hline Basse Normandie & 142 & 17430 & 139 & 17027 & -3 & $-2,31$ \\
\hline IDF & 1813 & 179053 & 1807 & 180161 & -6 & 0.62 \\
\hline Metropolitan France & 6902 & 774903 & 6949 & 780224 & 47 & 0.69 \\
\hline
\end{tabular}

This has been demonstrated by our model by identifying the effective demand in T0 period, which has allowed to estimate the effective demand for care in the coming years.

Thus, significant changes in number of births are estimated by 2020 in three regions of Metropolitan France, such as Rhône-Alpes, PACA and Midi-Pyrénées, which will welcome 2,305, 1,077 and 679 births more respectively. It should also be noted that despite a high concentration of practitioners in these regions, especially in Rhône-Alpes and PACA, the current supply of care will not be sufficient to cover the increase in population health care needs. Indeed, in order to satisfy the actual population demand in care without overloading practitioners (taking as a reference the average number of acts per region and per practitioner), the RhôneAlpes region will need 21 practitioners more in addition to the replacement of retired practitioners, the PACA region will need 14 practitioners more and the Midi-Pyrénées region 7 practitioners more (Table 2). Consequently, the numerus clausus should be increased in these regions.

The region of Brittany should be also mentioned with a slight decline in the number of births by 2020 ; however it would not have any impact on medical demography.

The proposed model also allows to identify a practitioner surplus in the Île-de-France region, which represents 6 practitioners. In this case, the numerus clausus for the Îlede-France region should be reduced by 6 . The practitioner surplus has its impact on the care consumption as well. Indeed, previous studies have proved the impact of the increasing number of practitioners on the care consumption. This phenomenon, which refers to Say's law of markets, has been analysed by health economist Robert Evans, who has determined that the increase in the number of practitioners will inevitably lead to an increase in the care consumption and so to the growth of health care costs [27]. 
Thus, basing on the proposed model results, we can conclude that the numerus clausus should be adjusted to the effective demand at region level in order to satisfy the population needs in health care in the coming years. A particular attention should be paid to the regions of Rhône-Alpes, PACA, Midi-Pyrénées and Île-de-France.

\section{Conclusion}

This research aims primarily to provide the most realistic territorial diagnosis in order to present an objective expertise to "public authorities". However, it is regrettable that the National Observatory of Health Professionals (ONDPS) still does not integrate in 2012 the impact of population ageing on the medical and surgical care in the calculation of the numerus clausus for each specialisation. Indeed, the simple replacement of retired doctors will not be enough to maintain the same level of activity for each practitioner. The impact of population ageing will inevitably lead to an increase of practitioners' activity. This is due to the fact that the delegation of medical tasks to paramedical practitioners does not reach unanimous agreement among health practitioners, on the one hand, and that the estimation of numerus clausus is based only on the number of retired practitioners, on the other hand.
Moreover, in terms of spatial equity, population will be unequally provided with healthcare which will be more and more dissociated from population real health needs. In geography, the paradigm is based on the principle that the knowledge of the "local" level allows to aggregate "larger spatial entities". This "Girondine" approach, so federalist, offers the best possible vision on care consumption in order to define then a precise geographic network. In these circumstances, the "dialectical game" of overlaying geographical scales allows to build the best possible matching between supply and "needs of care" of population, or rather, population effective demand for healthcare consumption.

\section{Conflict of interest statement}

The authors certify that they have NO affiliations with or involvement in any organization or entity with any financial interest (such as honoraria; educational grants; participation in speakers' bureaus; membership, employment, consultancies, stock ownership, or other equity interest; and expert testimony or patent-licensing arrangements), or non-financial interest (such as personal or professional relationships, affiliations, knowledge or beliefs) in the subject matter or materials discussed in this manuscript.

\section{References}

1. Zipf G. Human behavior and principle of least effort. Cambridge, Massachusetts: Addison-Wesley press; 1949.

2. Langlois J. Medical demography from 2003 to 2025 present and future difficulties. Bull Acad Natl Med. 2004;188(4):675691; discussion 691-693. https://www.ncbi.nlm.nih.gov/ pubmed/15587687

3. Huguier M, Romestaing P. Numerus clausus and medical demographics in France. Bull Acad Natl Med. 2014;198(7):1367-1378. https://www.ncbi.nlm.nih.gov/pubmed/27120909

4. Macé JM. Medical demography of surgeons in France. Report for International Center for Research in Health Economics CIRES, EN3S. St Etienne; 2007. French.

5. Benahmed N, De Wever A, Pirson M. Medical supply planning : dynamic registry of physicians, sixth reform of the State and numerus clausus. Rev Med Brux. 2017;38(2):103-111. https://www. ncbi.nlm.nih.gov/pubmed/28525252 French.

6. Picheral H, ed. Dictionary of Health Geography. Montpellier: Université Montpellier III-GEOS; 2001. French.

7. Credes. Territories and Access to Care: Report of the Working Group. 2003. French.
8. Scala A. Berkeley: Les Belles Lettres. Paris; 2007. French.

9. Kant E; Renault A, ed. Critique of Pure Reason. Paris; 1997. French.

10. Macé JM. Operational use of the actual health territory in planning. Villes en Parallèle. 2010;44:158-175. French. doi: 10.3406/ vilpa.2010.1479

11. Ciceri MF, Marchand B, Rimbert S. Introduction to the space analysis: collection of applicable Geography. Masson; 1977. French.

12. Terrier C. Tools (Ed.). INSEE Methodes. 1998;83:57-74. French.

13. Thouez JP. Spatial organization of care systems. Montreal: Presses de l'Université de Montréal; 1987. French.

14. Tonnellier F. Geography of care, economic geography, studies of various geographical contours in France. Paris: CREDES; 1990 French.

15. Macé JM, Picheral H. Territory experience: medical territory. In: Kervasdoue J. The health notebooks of France. Paris: Dunod; 2004:146-164. French.

16. Terrier C. Mirabelle. Paper presented at the Second international days on data analysis. Versailles; 1979. French. 
17. Terrier $\mathrm{C}$. The structures of the French space by alternating migrations. Paper presented at the Internal and External Migration in Western Europe, Lille. 1980. French.

18. Macé JM. Tools for hospital planning: the example of the Lagnysur-Marne hospital. Notebook on sociology and medical demography. 2003;43:115-148. French.

19. Macé JM. The threat of regional imbalances. Health Tribunes. 2006;12:45-55. French.

20. Macé JM. The notion of "territory" as a tool for health planning. Regards. 2007;31:97-111. French.

21. Brutel C. Projections of population by 2050: aging is inevitable. INSEE First. 2001:762. French.

22. Descours L, Poinat F. The demographic projection model OMPHALE. INSEE Méthodes. 1992;19:65. French.

23. Berger L, Mace JM, Ricco JB, Saporta G. Methodology for the evaluation of vascular surgery manpower in
France. Public Health. 2013;127(1):65-71. doi:10.1016/j. puhe.2012.09.002 Retrieved from https://www.ncbi.nlm.nih. gov/pubmed/23046888

24. Berger L, Mace JM. Vascular surgeons in France: an endangered species? Ann Vasc Surg. 2012;26(8):1154-1159. doi:10.1016/j. avsg.2012.03.005 Retrieved from https://www.ncbi.nlm.nih.gov/ pubmed/22819526

25. National Observatory of Health Professions (ONDPS). Report 2013-2014. 2014. French.

26. The Organisation for Economic Co-operation and Development. Health Panorama 2015. 2015. French.

27. Evans R. Supplier-Induced Demand: Some Empirical Evidence and Implications. In: Perlman M, editor. The Economics of Health and Medical Care. International Economic Association. London: Palgrave Macmillan; 1974:162-173. https://doi.org/10.1007/9781-349-63660-0_10 